\title{
Política editorial de traduções: John Dewey na Coleção Cultura, Sociedade e Educação, dirigida por Anísio Teixeira ${ }^{1}$
}

Maria Rita de Almeida Toledo²

\section{Resumo}

Analisa-se, neste artigo, o regime de tradução de dois títulos de John Dewey - Liberdade, liberalismo e educação e Experiência e educação - instaurado pela Coleção Cultura, Sociedade e Educação, dirigida por Anísio Teixeira e editada pela Companhia Editora Nacional (CEN) entre 1968 e 1971. Esta análise parte da perspectiva de que as traduções podem expressar práticas de intercâmbio cultural e circulação de ideias entre diferentes culturas, mas também estão marcadas pelos processos que as transformam em textos adaptados a públicos leitores específicos, ao serem editados e materializados em papel e tinta por políticas editoriais específicas que instauram regimes de tradutibilidade dos textos. Toma como fonte das traduções de Dewey a materialidade dos livros da coleção, seu aparelho crítico e a documentação interna da editora. Conclui-se que os textos de Dewey foram reunidos, traduzidos e editados por Anísio Teixeira na Coleção Cultura, Sociedade e Educação como um programa em favor da democracia em tempos difíceis os da ditadura civil-militar no Brasil e na América Latina - para um público comum. As traduções de Dewey conformam-se, sob a égide da coleção, como antídoto à violência, à palavra roubada, à supressão e à opressão da liberdade, expressões que deveriam compor toda e qualquer cultura comum ou geral de países democráticos.

\section{Palavras-chave}

Regime de tradução - John Dewey - Coleção Cultura, Sociedade e Educação - Materialidade do impresso.

1- Esta investigação é fruto de pesquisa financiada pelo Conselho Nacional de Desenvolvimento Científico e Tecnológico (CNPq), na forma de bolsa de produtividade em pesquisa.

2- Universidade Federal de São Paulo (Unifesp), São Paulo, SP, Brasil. Contato: mra.toledo@unifesp.br.

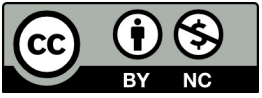




\section{Editorial politics on translations: J. Dewey in the collection Cultura, Sociedade e Educação (Culture, Society and Education), edited by Anísio Teixeira}

\section{Abstract}

This article analyzes the translation regime on two of John Dewey's works - Liberdade, Liberalismo e educação (Freedom, liberalism and education) and Experiência e educação (Experience and education) - set up by Coleção Cultura, Sociedade e Educação (Collection Culture, Society and Education), run by Anisio Teixeira and published by Companhia Editora Nacional (CEN), between 1968 and 1971. The assumption of the analysis is that translations might express cultural interchange practices and the circulation of ideas between different cultures. But they are also affected by the processes that turn them into adapted texts for specific readerships, when published and materialized in paper and ink by specific editorial policies that establish regimes that rule the translation of texts. The source is the translation of Dewey taken in the materiality of books in the collection, its critical apparatus and internal documents of the publishing company. The conclusion is that Dewey's texts were gathered, translated and edited by Anisio Teixeira at Coleção Cultura, Sociedade e Educação as a program for democracy in hard times - the civilianmilitary dictatorship in Brazil and in Latin America - to the ordinary public. Dewey's translations are, under the auspices of this collection, as an antidote to violence, to the stolen words, to the suppression and oppression of freedom, expressions that should make up all and every ordinary or general culture in democratic countries.

\section{Keywords}

Translation rules - John Dewey - Coleção Cultura, Sociedade e Educação - Publishing material.

Analisa-se neste artigo a política de traduções estabelecida pela coleção autoral, dirigida por Anísio Teixeira (1968-1971) na Companhia Editora Nacional, denominada Coleção Cultura, Sociedade e Educação, sob a qual foram traduzidos dois textos de John Dewey: Liberdade, liberalismo e educação e Experiência e educação. A perspectiva adotada para esta análise é a que toma os impressos como produtos culturais, frutos de lugares de poderes específicos que disputam a hegemonização de representações sobre as competências específicas de leitura e os modelos de formação adequados às práticas cotidianas dos leitores, inscritos em territórios específicos desenhados pelo editor. Tal problema de investigação remete às formalidades práticas que instituem regras, datadas e situadas, quanto aos modos de ler dos diferentes públicos para os quais diferentes textos são destinados, passíveis de serem analisadas tomando-se a materialidade dos impressos voltados para esses diferentes públicos (TOLEDO, 2013). 
Para este artigo é central a problematização das editoras e de suas práticas como lugar de poder, analisando suas estratégias (CERTEAU, 1990) articuladas às representações de leitores destinatários (CHARTIER, 1990) e à seleção dos saberes, dos autores e dos textos que põem em circulação. Esse problema de investigação eleva o editor - o "intermediário esquecido da literatura" (DARNTON, 2010, p. 150) - à figura principal das análises empreendidas ao longo das investigações propostas. Como mestre do mundo da edição, desenha projetos editoriais, adianta-se ao mercado, criando uma gama de produtos atraentes em territórios ainda a se constituir, mas também perscruta o público cativo, canonizando autores e obras, retroalimentando territórios já constituídos, produzindo uma espécie de geografia cultural. ${ }^{3}$ É na fábrica capitalista comandada por esse mestre que um universo específico da produção se constitui: o "livro é a um só tempo produto fabricado industrialmente em máquinas [...], e entregue empacotado como latinhas de coca-cola, e um objeto cultural irredutivel a essa dimensão única” (MOLLIER, 2011, p. 66).

Para se compreenderem as práticas editorias e seu lugar no ciclo de produção de diferentes geografias culturais do impresso, é preciso dimensionar as relações de permanente tensão que mantêm com outras estratégias, emanadas de outros lugares próprios de poder - como o Estado, a Igreja, a universidade, a escola ou outras casas de edição. As políticas culturais e econômicas engendradas por esses outros lugares facilitam ou limitam a produção editorial, determinando estratégias de adesão ou resistência das editoras. Além disso, deve-se levar em consideração a questão do mercado leitor como objeto das estratégias editorias, mas também como sujeito referente, cujas apropriações da geografia cultural da edição podem surpreender ou alterar os seus rumos.

Com essa perspectiva, a presente análise toma o caso das traduções culturais de John Dewey editadas na Companhia Editora Nacional (CEN) entre 1933 e 1981, situando as geografias culturais nas quais as práticas de tradução e edição dos textos desse autor se processaram. Por isso mesmo é importante destacar que J. Dewey foi traduzido nessa casa editora sempre como volume de alguma coleção autoral. Assim, por exemplo, Como pensamos e Democracia e educação apareceram na Coleção Atualidades Pedagógicas, assinada por Fernando de Azevedo e depois, por João Batista Damasco Penna; Liberdade, liberalismo e educação e Experiência e educação, como já indicado, foram editados na Coleção Cultura, Sociedade e Educação, assinada por Anísio Teixeira.

As traduções editadas em coleções de livros têm uma especificidade: sua publicação como volumes de uma coleção produz, para além da operação linguística de versão do texto original em outra língua, alterações de sentido que não podem ser menosprezadas. A intervenção dos chamados dispositivos editoriais e textuais de modelização da leitura (CHARTIER, 1990) - como a escolha de um padrão de cobertura (capa, lombada, quarta-capa), de estruturação interna e de estratégias de divulgação - opera a padronização dos volumes publicados, produzindo a identidade da coleção. Mas é principalmente o que Olivero (1999) designa como aparelho crítico - prefácios; notas do tradutor ou do editor e comentários introduzidos nos volumes; índices remissivo e onomástico; exercícios; sumários; etc. - que

3- A noção de geografia cultural está em diálogo com a noção de ordem dos livros proposta por Chartier (1994) e com a noção de lugar próprio, proposta por Certeau (1990, p. 60), enfatizando as práticas dos editores de classificação dos saberes em seus catálogos. 
produz alterações de sentido nos textos traduzidos e publicados. Por essa perspectiva, torna-se central a análise da materialidade dos livros (TOLED0; CARVALHO, 2017).

0 gênero editorial coleção, desde seu nome, dá a ver a prescrição de seus leitores destinatários e de seus usos prescritos. Nesse sentido, suas regras de organização material são flexíveis e permitem sua adequação às condições do mercado, seja para conquistar novos leitores, seja para ampliar o consumo do público contumaz. Tal estratégia editorial estabelece, no quadro da expansão e especialização da indústria do livro, a necessidade de editores diretores de coleção, especializados nos mercados visados pelos programas de leitura das coleções. ${ }^{4}$ Nesses termos, surgem nas editoras hierarquias entre o editor-chefe e os editores mais ou menos especializados nos diferentes nichos do mercado.

A dinâmica de produção das coleções é afeita a associações de projetos prescritivos de formação de leitores, porque estabelece uma determinada ordem para as leituras, em termos de sequência, em termos de combinação de autores e conteúdos, mas também pela sua capacidade de didatização, inscrita nos dispositivos materiais e tipográficos, dos textos nela impressos (TOLED0, 2013). Além disso, as coleções podem adotar como marca de sua produção um nome de destaque para sua direção geral, articulando os projetos prescritivos ao crivo de intelectuais de renome e transformando-se em coleções autorais (TOLED0, 2013).

No caso da Companhia Editora Nacional, essas diferenciações entre diretores de coleção convidados e editores do staff eram explícitas, com divisões de tarefas claras. Cabia aos diretores convidados selecionar títulos e autores, preparar as orelhas das capas e os textos de apresentação, selecionar tradutores, cuidar da qualidade dos textos e interferir em negociações de contrato, quando necessário usar de seus prestígios, enquanto os editores negociavam os contratos, organizavam a produção material dos títulos - indicando capistas, tradutores, revisores - e se encarregavam dos trabalhos de supervisão do processo de impressão, dos pagamentos e da distribuição, entre outras práticas do cotidiano da fábrica. Se Anísio Teixeira, João Batista Damasco Penna ou Jacobina Lacombe, entre outros diretores, tinham como encargos cuidar da programação de suas coleções e zelar pela qualidade das publicações, Luiz Roberto Malta, ${ }^{5}$ Thomáz Aquino Queiróz, ${ }^{6}$ entre outros, cuidavam do cotidiano da fábrica. Todos sob a batuta do Big Boss - como era conhecido o dono da editora - Octalles Marcondes Ferreira. ${ }^{7}$

Ainda, se, de um lado, as traduções expressam as práticas de intercâmbio cultural e circulação de ideias entre diferentes culturas, de outro, elas estão marcadas pelos processos que as transformam em texto editado, materializado em papel e tinta, destinado a públicos definidos em políticas editoriais específicas, como as que dão origem a coleções da Companhia Editora Nacional. Nesse sentido, ressalta Burke (2009, p. 14): as práticas de tradução devem ser entendidas como práticas de "tradução cultural", já que as "diferenças entre culturas, bem como entre línguas, reduzem a tradutibilidade dos textos”. As práticas

4- Para uma história do nascimento das coleções na França, cf. Olivero (1999) e Mollier (2010, 2011). Sobre o contexto brasileiro, cf. Toledo (2001).

5- Luiz Roberto Malta era o editor chefe da área de produção da Companhia Editora Nacional.

6- Thomáz de Aquino Queiróz era o principal editor do Departamento Editorial e de Produção.

7- 0 nome de Octalles Marcondes Ferreira aparece grafado de várias formas: Othales, Octhales, Octales, Octalles. Adotou-se essa última forma porque assim aparece em documentos oficiais. 
dos tradutores e agentes envolvidos na circulação dessa espécie peculiar de escrita “tentam manter a fidelidade original de um texto articuladas às possibilidades de decifração do mesmo pelos seus leitores” (BURKE, 2009, p. 14). É necessário, segundo Burke (2009, p. 14), situar esses textos traduzidos em seu contexto cultural, de modo a localizar os "sistemas ou regimes de tradução prevalecentes em seu tempo presente", ou "as regras, normas ou convenções que governavam sua prática, levando-se em consideração tanto os seus fins (ou 'estratégias'), como seus os meios (as 'táticas' ou 'poéticas')".

Como prática integrada à fórmula editorial de uma coleção, a lógica que precede as traduções culturais - ou seu regime de tradução - acompanha as próprias práticas que dão sentido a determinada coleção. A análise do ato de escolha e tradução de determinados textos sob as regras intrínsecas das coleções permite a especificação dos procedimentos pelos quais determinados autores e obras são apropriados para comporem essas intervenções culturais.

Sob essa chave analítica, coloco em foco a conjuntura que levou Anísio Teixeira a escolher e traduzir os textos Liberalism \& social action e Freedom and culture, sob o título Liberalismo, liberdade e cultura (1970), e Experience and education, sob o título Experiência e educação (1971), todos de John Dewey, editados na Coleção Cultura, Sociedade e Educação. Para tal investigação, apresento as representações de Teixeira sobre as regras e normas do bem traduzir, assim como os critérios fundamentais de seleção dos textos de sua coleção, para compreender o território cultural que com ela construiu e o lugar em que inscreveu a obra de J. Dewey.

\section{A fórmula editorial da Coleção Cultura, Sociedade e Educação e a constituição de um novo território para a educação}

A Coleção Cultura, Sociedade e Educação (CCSE) é lançada oficialmente em 1968 e desaparece junto com seu editor em 1971, publicando um último volume em 1972.

Para a análise dessa coleção e do processo de sua montagem e desmontagem, é importante lembrar que, dentro da CEN, Anísio Teixeira assumiu diversas funções durante os 42 anos de relação que com ela estabeleceu: foi autor, tradutor, consultor e editor. Nos catálogos da Nacional, o nome de Teixeira aparece nessas diferentes funções. Essa antiga relação entre Octalles Marcondes Ferreira e Anísio Teixeira permitiu que o intelectual fosse contratado pela editora em 1966 para ser um editor de seu corpo de funcionários e que a editora abrigasse mais uma coleção assinada por Teixeira - a Coleção Cultura, Sociedade e Educação, cujo desenho era bastante ousado -, além da já existente Biblioteca do Espírito Moderno, também editada por ele desde 1939. ${ }^{8}$

Naquele ano de 1966, a situação de Anísio Teixeira era bastante complicada no Brasil. Entre 1951 e 1964, o intelectual atuara junto ao governo federal de modo intenso: foi chamado logo em 1951 para coordenar a Comissão de Aperfeiçoamento do Pessoal do Ensino Superior (CAPES), fundada em junho daquele ano e logo transformada em órgão

8- Para uma história dessa coleção, consultar Fonseca (2010). 
para desenvolver a pós-graduação no país; em 1952, foi convidado para ocupar o cargo de diretor do Instituto Nacional de Estudos Pedagógicos (INEP), permanecendo nos dois lugares até o golpe de 1964, quando, em 27 de abril, foi aposentado compulsoriamente (NUNES, 2000). Ainda, em 1962, durante o governo João Goulart, foi convidado para ser conselheiro do Conselho Federal de Educação, permanecendo no cargo até o fim de seu mandato, em 1968, sem recondução. Com a aposentadoria e uma autorização especial do Presidente Castello Branco, parte para os Estados Unidos para lecionar como professor convidado nas universidades de Columbia, Nova York e Califórnia, retornando ao Brasil em meados de 1966, sendo imediatamente contratado pela CEN.

Nessa posição, Anísio Teixeira passa a ter as funções de: garimpar títulos e autores para serem incluídos no catálogo da Nacional; dar pareceres sobre títulos e autores escolhidos pelos editores da casa ou oferecidos por outras vias - indicados por instituições, editoras, agentes literários ou universidades e fundações -; dar opinião sobre reedições, propostas de coleções, qualidade de traduções; e, ainda, mediar negociações de liberação de direitos autorais/direitos de tradução ou apoio a projetos editoriais entre a Nacional e outras importantes instituições culturais, como o INEP e a Embaixada dos EUA. Assim, credenciava a editora com seu renome, reconhecido nacional e internacionalmente.

Em carta, Octalles Marcondes Ferreira comenta:

Anísio,

[...] cada vez mais, me convenço do acerto de nossa idéia de colocá-lo dentro da Editora, pois você é a pessoa indicada para exercer o papel que eu precisava, para dar um sentido elevado ao programa editorial da Companhia. Creio que se o Brasil não parar, se tivermos recursos (até onde nos levará a inflação?) e saúde, juntos, ainda poderemos fazer muito pelo desenvolvimento cultural do Brasil. (FERREIRA, 9 set. 1966).

0 nascimento da Coleção Cultura, Sociedade e Educação vem no bojo dos trabalhos realizados por Teixeira junto à CEN e seu desenho é gestado ao longo de 1966 e 1967, momento em que há a expectativa dos editores da casa de renovação do catálogo. Além de novas coleções assinadas por Teixeira, Marcondes Ferreira projetava reeditar toda a sua obra como obras reunidas. São esses projetos que passam a figurar como tarefas centrais de Teixeira na editora.

As novas coleções a serem dirigidas por Teixeira começam a ser nominadas, em setembro de 1966, de Brasiliana Contemporânea e Biblioteca de Educação, Ciência e Cultura (BECC). Para a Brasiliana Contemporânea, o próprio Ferreira explica a Teixeira que iniciara negociações com Dr. Jacobina Lacombe para que essa coleção fosse uma série da antiga Brasiliana - dirigida por este desde o final dos anos 1940. Essa negociação significava a partilha do tradicional território da Coleção, que se dedicava a tornar mais conhecido o Brasil para os brasileiros. A renovação se daria por meio da publicação de textos escolhidos por Teixeira que tivessem sido produzidos após $1900 .^{9}$

9- Escreve Teixeira: "Thomaz: 1'Os dois Brasis'de J. Lambert deve ficar na Brasiliana Contemporânea, que incluirá livros importantes sobre o Brasil publicados após 1900. Não sei, porém, se Octales aprovou em definitivo o título Brasiliana Contemporânea ou Brasiliana Moderna. Contemporânea parece-me mais próprio" (TEXEIRA, 28 out. 1966). 
Mas o staff projetava para Teixeira outra partilha de território alheio, o ocupado por João Batista Damasco Penna, diretor da Atualidades Pedagógicas desde 1946, com o projeto da coleção Biblioteca de Educação, Ciência e Cultura (BECC).

Em carta, Teixeira explica a Queiróz as suas expectativas sobre o desenho da nova coleção: "Estou satisfeito que tenha a CEN obtido a opção para The Schools de Martin Mayers. Este será um dos novos livros para a leitura de todos e não apenas dos pedagogos. Deverá aparecer na coleção sugerida de educação, ciência e cultura ou outro nome que venha a ter." (TEIXEIRA, 2 dez. 1966, grifo do autor).

Com o novo projeto, Teixeira inaugura uma discussão interna à editora cujo argumento central era a necessidade de redesenhar o território da educação e seu público, sem confundi-los com o território da pedagogia e com o público dos pedagogos. Para ele, a educação deveria ser assunto de todos os interessados e não deveria ser territorializada no campo da pedagogia, deslocando, assim, desse território editorial leituras e autores. Ainda na mesma carta, volta à carga ao assinalar a importância da reedição de um de seus autores prediletos - John Dewey -, editado na coleção para mestres e pedagogos, Atualidades Pedagógicas, desde 1936:

A minha reserva sobre Atualidades Pedagógicas é que certos livros não são atualidades nem pedagógicas. São livros de cultura geral, de filosofia, de ciências sociais. Tome, por exemplo, Democracy and education de J. Dewey. 0 endereço deste livro é muito mais amplo do que os dos mestres pedagogos. É uma filosofia da democracia. Lembre-se que Dewey explicitamente afırma que a filosofia é uma teoria de educação. 0 livro deve ser reeditado sem menor dúvida, embora eu gostasse que a tradução fosse refeita, mas já que isso não se possa fazer, que saia numa edição para o grande público, ou, pelo menos, todo o público intelectual e não apenas, repito, o dos pedagogos e professores (infelizmente com o pedagógico apenas os primários). Converse pois com Penna. (TEIXEIRA, 2 dez. 1966, grifo do autor).

0 movimento de reterritorialização da educação no catálogo da editora, levado a cabo por Teixeira, foi contemporâneo às negociações da reedição de Democracy and education. A possibilidade dada a Teixeira de projetar estratégias de ampliação do público para esse título também lhe possibilitou espaços de transferência do autor e de sua obra para sua própria coleção.

Publicado, até então, três vezes na Atualidades Pedagógicas (em 1936, 1952 e 1959), na avaliação dos editores, apesar de sua importância capital, o livro não fora vendido nem em escala, nem em velocidade. Em carta de negociação da reedição desse título com a Macmillan, Luiz Roberto Malta apresenta a proposta: "We are considering seriously a new edition of this title, since we believe it in a book of capital importance for all people concerned with the educational problems, in spite of being, on the other hand, a book whose sales would not be too big or too quick." (MALTA, 8 mar. 1967). ${ }^{10}$

10- "Estamos considerando seriamente uma nova edição deste título, já que acreditamos ser este um livro de importância capital para todas as pessoas preocupadas com os problemas educacionais, apesar de ser, por outro lado, um livro cujas vendas não seriam muito grandes ou muito rápidas" (tradução livre). 
Por isso, seu relançamento deveria ser acompanhado de novas estratégias editoriais que ampliassem seu público. A primeira estratégia, aventada por Ferreira e Luiz Roberto Malta, era a de uma nova tradução, convidando para isso o próprio Anísio Teixeira. No entanto, Teixeira entendia que a melhor forma de atrair o público para a obra de Dewey seria a de preparar sua recepção com a edição dos textos mais simples do próprio autor, como Vida e educação - primeiros textos traduzidos por ele mesmo nos anos 1920. ${ }^{11}$ Ao responder ao convite para a tradução de Democracy and education, propõe a Ferreira:

\begin{abstract}
Nada me fascinaria mais, não fosse o medo de enfrentar aquelas densas 500 páginas. Vou, porém, pensar muito no projeto. Antes disso, contudo, desejo lhe sugerir re-editar nas Atualidades - Vida e educação de Dewey. Esse pequeno volume merece uma edição. Estou certo de que, devidamente apresentado, com aspecto de livro novo e atual, pode conquistar, de novo, a profusão de leitura que sempre teve. Para isto, muito ganharia se a ele acrescentássemos o livrinho último de Dewey - Experience and education - publicado pela última vez, se não me engano, na década de 40. Poderia, antes de Democracy and education, traduzir este pequeno livro e editarmos ainda em 1967 esses dois volumes de Dewey que preparariam a saída, em 1968, do Democracy and education, o livro de peso de Dewey. (TEIXEIRA, 13 mar. 1967, grifos do autor).
\end{abstract}

Tal estratégia ainda seria ampliada com a articulação dos lançamentos dos dois livros de Dewey e com um dos títulos introdutórios da filosofia desse autor, escrito por Teixeira, em 1933, Educação progressiva, também lançado na Atualidades Pedagógicas. Ferreira aceita imediatamente a proposta de Teixeira, providenciando as negociações dos títulos com a Cia Melhoramentos - detentora dos direitos de tradução de Vida e educação - e com a Macmillan Co. - detentora dos direitos de Experience and education.

Contudo, com o projeto da tradução de Experience and education aprovado, Teixeira muda de ideia e começa a projetar a edição de seus próprios livros e a dos de Dewey na coleção que dirigiria. Teixeira argumenta com os editores que não via com bons olhos a alocação de sua obra na Atualidades Pedagógicas de Penna. Em carta a Queiróz, ele explica a necessidade de reterritorializar o campo da educação em relação à pedagogia e à cultura:

Meu Caro Thomáz: estou hoje devolvendo as provas de Educação Progressiva e isto dá-me oportunidade para lhe falar sobre a coleção para a inclusão dos meus livrinhos. Minha reserva quanto à Atualidades Pedagógicas prende-se à designação da coleção e não aos seus propósitos e fins. Como escrevo mais para o leigo do que para o especialista, julgo que meus livros não são suficientemente "pedagógicos" para o leitor da Atualidades, perdendo os seus leitores, e, porque saem na coleção pedagógica, perco também os leitores da cultura geral. Preferia, assim, aparecer na BECC. Creio que mais cedo ou mais tarde, Penna verá que Atualidades Pedagógicas não constitui título para uma coleção de Educação. No caso dos meus livros saírem como uma série ou cousa que o valha, gostaria, como já disse, que aparecessem na BECC, com uma referência à AP quando o livro tivesse sido originalmente ali publicado. (TEIXEIRA, 19 maio 1967, grifo do autor).

11- Para uma análise da tradução cultural de Vida e educação pela Cia Melhoramentos, em 1930, cf. Toledo e Carvalho (2017). 
Se, de um lado, essa proposta desarticulava o conjunto Dewey / Educação progressiva na Atualidades Pedagógicas, de outro, abria espaço para negociações da transferência da obra de Dewey para a nova coleção de Teixeira. A partir daí, estabelece-se uma queda de braços entre Teixeira e Damasco Penna pelos títulos e autores que interessavam ao programa das duas coleções. ${ }^{12}$

Pode-se inferir que, nessa queda de braços, para fortalecer sua posição e reterritorializar a educação na cultura, Teixeira resolve fundir a Brasiliana Contemporânea e a BECC. Em carta para Ferreira, justifica-se:

Diante da inevitável lentidão da saída de um novo livro e da sua justificada prudência quanto à aventura de novas coleções, estou indeciso quanto à Coleção Educação, Ciência e Cultura. Estou com receio da inclusão de Ciência, que só por si é um mundo. Quem sabe se não poderia ser Cultura, Educação e Sociedade? Assim estaríamos apenas, no fundo, com Ciências Sociais, o que estaria melhor no meu campo. Começaríamos a coleção com Cultura e Sociedade de Raymond Williams. Este é um ponto que queria examinar com V. Não desejo alterar as bases das coleções existentes, nem dar base para qualquer susceptibilidade dos seus diretores. Em agosto conversamos, a sugestão é somente para V. pensar no novo nome. (TEIXEIRA, 19 jun. 1967, grifo do autor).

Nos lugares da BECC e da Brasiliana Contemporânea, nasce, em 1968, a Coleção Cultura, Sociedade e Educação (CCSE). A CCSE, como ficou conhecida por meio de seu logotipo, estava voltada para o público de educadores, mas pretendia alcançar um público mais amplo, sobretudo, aquele interessado na cultura geral. Por isso, o repertório da coleção deveria ser composto não apenas por temas afeitos ao campo da educação, mas pelos estudos culturais. Educação, nesse sentido, era parte da cultura e nela deveria ser lida, assim como a educação deveria ser lida pelos que se interessassem pela cultura. Sua coleção territorializava a educação entre as ciências sociais e a cultura, redimensionando o conjunto de leituras e de seus leitores, inclusive as já editadas na própria Nacional, deslocando-a de coleções como a Atualidades Pedagógicas. Com a palavra cultura no título da coleção, Teixeira poderia editar os títulos destinados, em princípio, para a Brasiliana Contemporânea, sem entrar em conflito com Jacobina Lacombe.

Em carta a Queiróz sobre a possível alocação de La pensée sauvage, de Lévi-Strauss, explica o sentido que atribuía à sua coleção "mas, não desejo incluir o livro em nossa Coleção Cultura, Sociedade e Educação. La pensée sauvage é muito mais livro universitário que de cultura comum, não pretendo alargar até aí os propósitos da pequena coleção nova." (TEIXEIRA, 5 fev. 1968, grifo do autor).

Ainda, reforçando sua posição política perante o que a editora e Damasco Penna vinham traduzindo para o mercado de educação e para o mercado do ensino superior, Teixeira, em carta a Ferreira, insiste sobre os sentidos da cultura e a formação do leitor:

12- Para uma análise desse conflito, cf. Toledo (2007). 
[...] a tradução necessária para o Brasil seria de livros para a cultura geral e, com especialidade, de livros de pensamento original, que constituíssem fonte da cultura humana, menos para os especialistas do que para o leitor comum. Livros de exposição dos conhecimentos existentes, manuais didáticos, tratados sistematizados de conhecimento e outros que tais seriam obras de autores nacionais a estimular e organizar [a cultura especializada]. (TEIXEIRA, 26 jan. 1968).

É dessa representação do que deveria ser traduzido e do lugar da educação na geografia cultural da editora que Teixeira desenha o modelo de leitura e formação da CCSE. Assim, a CCSE constituiu-se pela oferta direta de textos originais em traduções, entendidas pelo seu diretor como aqueles que deveriam compor um repertório fundamental para a formação do leitor, acrescidos de especialistas brasileiros da área de educação. 0 próprio nome da coleção já apontava nessa direção, destacando cultura e educação na sua evidente triangulação com a sociedade, e tomava, de certa forma, o modo peculiar com o qual Williams atribuía significado para essa triangulação no último capítulo de sua obra Cultura e sociedade.

Nessa perspectiva, não havia espaço entre os títulos escolhidos para manuais ou compêndios sobre as áreas do conhecimento que o repertório da coleção cobria - educação, ciências sociais, política ou sociologia. 0 leitor comum, na perspectiva de Teixeira, deveria ler o que havia de mais sofısticado para a sua formação geral, mas nunca manuais gerais, com os conhecimentos didatizados pasteurizados. Ao mesmo tempo, não precisava ler textos muito específicos, com discussões extremamente acadêmicas, como La pensée sauvage. As escolha dos títulos, portanto, recaíam sobre textos que dessem tratamento aos temas da cultura de um ponto de vista disciplinar, mas que pudessem conformar a cultura comum.

No projeto inicial, Teixeira escolhe 13 títulos diretamente voltados para a discussão de aspectos do campo da educação/pedagógico; outros sete, segundo as classificações do catálogo da própria editora, pertenciam às áreas da política (2), da sociologia (4) e das ciências sociais (1). ${ }^{13}$

O conjunto sobre educação compunha-se de sete obras de brasileiros, sendo cinco delas de autoria do próprio Anísio Teixeira e outras duas de Hélio Pontes e Terezinha Éboli. Seis autores foram escolhidos para serem traduzidos: J. Dewey, J. Bruner, Alfred N. Whitehead, John Pfeiffer, James Bryant Conant e W. Kenneth Richmond. Como se vê, as obras do próprio editor davam o enquadre para as análises educacionais, intercaladas às traduções de textos norte-americanos e ingleses.

Já o conjunto sobre ciências sociais - incluindo seus subcampos - compunha-se, exclusivamente, de autores estrangeiros, vertidos para o português. Os autores programados eram: J. Dewey (1), Raymond Williams (2), Jacques Lambert (1), Peter Winch (1), Alexis de Tocqueville (1) e Marshall McLuhan (1). Com exceção da obra de J. Lambert, todos os outros títulos foram vertidos do inglês para o português especialmente para essa coleção. Como se vê, Dewey não era classificado apenas no território da educação, transitando na apresentação do catálogo da editora entre mais de uma área do conhecimento.

13- As informações que seguem foram tiradas da documentação interna da editora, sobretudo das fichas de Movimento de Edição da coleção. 
Teixeira escolheu preferencialmente títulos anglo-saxões para oferecer ao leitor brasileiro e, neles, as ênfases nas análises das mudanças culturais no mundo capitalista e nas mudanças educacionais especificamente. Parte dos títulos e autores escolhidos por Teixeira eram completa novidade no mercado editorial e intelectual do Brasil. Se Dewey, Lambert e Tocqueville já frequentavam as bibliotecas brasileiras, McLuhan, Williams e Winch eram novidades, considerados textos polêmicos que, em suas respectivas áreas, traziam novos problemas para pensar a cultura.

No entanto, nota-se que há diferenças entre o desenho projetado para a coleção e o que de fato se concretizou. Tomando-se a lista dos títulos programados para a publicação da CCSE - 20 títulos ao todo -, nota-se que apenas 18 foram efetivamente editados. ${ }^{14}$

Ainda, é possível notar que a expectativa de vendas dos volumes da coleção não era baixa, já que os títulos saíram com tiragens entre 3.000 e 5.000 exemplares. Contudo, no curto período de existência da coleção, apenas duas obras foram reeditadas, todas elas de Anísio Teixeira, indicando a baixa aceitação do público leitor quanto ao projeto editorial assinado por esse intelectual.

É sob essa fórmula editorial que o lugar de Dewey é redirecionado, passando a ser um referente da cultura geral e da cultura comum, no lugar do território da pedagogia, como aparecia entre os volumes da Atualidades Pedagógicas. ${ }^{15}$

No texto da orelha de Experiência e educação, seu editor apresenta a importância do texto para o leitor: "Este pequeno livro é um grande livro. Experiência e Educação oferece aos educadores e mestres - e também ao mundo de cultura geral, pois todos hoje tem interesse e preocupação em educar e ensinar - uma filosofia positiva da educação.” (COMPANHIA EDITORA NACIONAL, 1971, orelha).

Mas a articulação entre educação, cultura e sociedade, no programa da coleção, não servia apenas para reterritorializar Dewey e a educação, como aparece no excerto citado. Para o editor, essa triangulação era importante instrumento na tarefa urgente de analisar aquilo que Teixeira entendia ser a crise atual. A representação do que seria essa crise e as análises que a identificariam e a dirimiriam ao leitor e ao próprio editor eram crivos das escolhas de Teixeira, pelo menos para as traduções programadas na CCSE. Neste sentido, a coleção parece voltada para fazer uma radiografia do presente e de suas raízes culturais. Nos paratextos da CCSE - orelhas, notas e prefácios -, Teixeira procura justificar a publicação dos volumes, mesmo quando se tratava de seus próprios títulos, utilizando-se do argumento de sua utilidade para o presente.

Por exemplo, para o primeiro volume da coleção, Anísio Teixeira justifica o percurso realizado pelo autor - análise do pensamento social de 40 autores ingleses entre 1780 e 1950 - para descrever o impasse da crise cultural daquele tempo, dirimida em Sociedade e cultura:

0 livro nos traz até 1950, quando entramos nas décadas mais recentes, tão novas e desconcertantes, com o existencialismo e tudo que lhe vem sucedendo, em que nos sentimos divididos entre o

14- The long revolution, também de Williams, não foi editado pela baixa aceitação do mercado de Cultura e sociedade; e o texto de Bruner foi editado na coleção Atualidades Pedagógicas, depois da morte de Teixeira.

15- Para uma análise do lugar destinado a Dewey na Atualidades Pedagógicas ao longo do tempo, cf. Toledo (2013). 
movimento da mocidade, cheio de promessa e mistério, e uma espécie de novo-vitorianismo dos conservadores, cheios de duvidoso sentimento de onipotência e muitas vezes vazios de imaginação. Seu símile histórico talvez possa ser o declínio romano e a fermentação evangélica e cristã. (COMPANHIA EDITORA NACIONAL, 1968, orelha).

A função de instrumento analítico da crise presente, atribuída ao texto, é reforçada pelo último parágrafo da orelha: "Para compreender e explicar a perplexidade e o mistério do nosso tempo, julgamos ser indispensável a leitura desta paciente, difícil, penetrante e, sobretudo, otimista descrição e análise de Raymond Williams" (COMPANHIA EDITORA NACIONAL, 1968, orelha).

A ideia de crise atravessa a coleção, ordenando os discursos dos autores ali reunidos. Assim, os livros de Dewey selecionados para a coleção aparecem com a função de analisar e dirimir as névoas e a neblina do tempo presente. No mesmo texto da orelha de Experiência e educação, argumenta:

Educadores profissionais ou leigos juntos encontrarão nestas páginas respostas definidas à maior parte de suas questões, respostas que constituem parte integrante de uma filosofia da educação que torna possível o esforço unido e conjunto dos líderes do nosso tempo. Traz esse livrinho uma nova luz que dissolverá a neblina e as névoas que hoje envolvem filosofia e teoria de educação. (COMPANHIA EDITORA NACIONAL, 1971, orelha).

A escolha do termo crise, provavelmente, está demarcada pela própria situação que Teixeira vinha sofrendo desde o golpe militar, em 1964. Daí é possível inferir que a coleção pode ter servido a seu editor como forma de fazer circular suas representações sobre educação, cultura e democracia, usando discursos alheios. Em carta a Queiróz, Teixeira comenta:

1) estou a lhe mandar a nota introdutória que confesso não saber se convém a "Liberalismo, Liberdade e Cultura”. Trata-se de artigo escrito para as Fôlhas por ocasião da tradução. Escrever mesmo uma nota introdutória envolveria inevitavelmente referência à situação local e não desejo fazê-lo por faltar-me liberdade para isto.

Acredito, contudo, que bastará a referência implícita e o silêncio dos editôres. [...] Acho que certos livros são mensagens que precisam ser publicadas, não tanto para atender o presente, mas para servir ao futuro. (TEIXEIRA, 20 jan. 1970, grifo do autor).

Mas a dimensão da crise parece também ultrapassar as questões locais e exigir análises amplas das mudanças que o século XX atravessava. É com esse argumento que Teixeira também justifica a escolha de dois textos de Dewey reunidos no já citado volume, Liberalismo, liberdade e cultura. No texto da orelha, argumenta:

Publicamos, em conjunto, dois notáveis trabalhos de John Dewey, escritos na década de trinta, marcada pelas revoluções totalitárias do fascismo e do nazismo, que sucederam à revolução comunista russa. Ambos os documentos ganham nessa década de 70 uma atualidade indiscutível na América Latina e, talvez, no mundo. Acreditamos que a afırmação de fé de um dos maiores 
filósofos contemporâneos na liberdade, na democracia e na revisão do liberalismo como política fundamental dos dias presentes, constitui uma lição e um exemplo para a nossa atualidade. (COMPANHIA EDITORA NACIONAL, 1970, orelha).

0 diretor pretendia dispor ao leitor textos fundamentais vertidos para o português, o que implicava, no programa editorial que construía, um cuidado extremo com os textos traduzidos. Daí também decorria todo o cuidado do editor em trabalhar as traduções, oferecendo material de alto nível para o leitor comum. Por isso, Anísio Teixeira revisou todas elas, fazendo jus a seu lugar de editor.

Mas essa obsessão com a qualidade das traduções também expressava todo um movimento por parte dos tradutores profissionais que pretendiam instaurar novas regras de avaliação e qualidade das traduções, expurgando do mercado as traduções livres ou literárias, muito praticadas na própria CEN, em tempos em que Monteiro Lobato era um de seus principais editores e tradutores.

Circulando entre os tradutores que vinham alimentando o debate sobre a questão da tradução no Brasil - Paulo Ronái e Aurélio Buarque de Hollanda Ferreira, entre outros -, Teixeira passa a adotar esses critérios na seleção e na avaliação dos tradutores que poderiam compor sua nova coleção.

Em carta, Queiróz comenta a avalição que Teixeira havia feito de um candidato a tradutor do livro Cultura e sociedade:

Prezado Dr. Anísio,

Acabo de receber, pelo Jairo, seu bilhete de ontem sobre o teste de tradução feito sobre o livro de Raymond Williams. "Muito obrigado".

Seu julgamento foi implacável... Mas está certíssimo quando diz que o tradutor para um livro como esse não pode deixar de ser também escritor,... e dos bons. 0 que não ocorre com o nosso candidato. (QUEIRÓZ, 19 out. 1966, grifo do autor).

0 mesmo severo julgamento aparece na avaliação que Teixeira faz de uma nova candidatura de tradutores ao texto de Williams.

Meu Caro Thomaz,

Não quero retardar minha impressão do novo teste de tradução do Raymond Williams. Acho que os tradutores compreenderam o texto e o traduziram muito melhor do que o primeiro. Penso, entretanto, que podem melhorar muito a tradução.

Williams escreve com o que poderia chamar a "maneira" - para não dizer estilo oxfordiano, buscando não fugir à clareza, mas ao didático. 0 pensamento toma os ares de antes estar sendo sugerido do que descrito. Daí, a aparência de obscuridade. 0 seu estilo procura deixar claro que está procurando formular os seus julgamentos e que não os tem todos prontos para passar ao leitor. 0 tradutor notou, de certo, isto e procurou traduzir com excessiva fidelidade. Mas agora que viu o que Williams quis significar, pode muito bem aperfeiçoar o texto e dar-lhe o gosto do português tão escorreito quanto possível. (TEIXEIRA, 8 nov. 1966, grifos do autor). 
Paulo Ronái, em seus artigos reunidos no livro Escola de tradutores, editado pela primeira vez em 1952, insistia que as traduções literárias ou adaptadas, muito recorrentes no Brasil, deveriam ser abandonadas em favor de traduções que procurassem a máxima fidelidade aos textos originais. Isso, segundo o autor, implicava um conhecimento enorme sobre a língua traduzida e sobre a língua para a qual o texto era vertido: "Uma versão literal, isto é, fiel a apenas uma das duas línguas [seria] impossível” (RONÁI, 2012, p. 21). 0 tradutor competente deveria trabalhar com o espirito da lingua para a qual traduz, sem, no entanto, alterar o estilo do autor traduzido. Esse conhecimento do espírito das línguas e dos estilos dos autores traduzidos seriam dois importantes critérios para se verificar a qualidade das traduções oferecidas aos leitores. Por isso, na avaliação do tradutor, muitas das traduções de famosos literatos eram de péssima qualidade, porque estes tendiam a impor seu próprio estilo ao texto vertido para o português.

Como se vê, Teixeira partilhava as representações de Ronái sobre a boa tradução, adotando-as como base para a publicação dos textos de sua coleção.

Nesses mesmos termos julgava suas próprias traduções. Em carta a Queiróz e Malta, Teixeira apresenta suas angústias em relação ao ato de traduzir:

\begin{abstract}
Meus Caros Thomaz e Malta:
[...] A revisão, fi-la com severidade: valeu-me para mostrar que sou tão pobre tradutor quanto aqueles que tenho procurado rever. Não me desconcerta isto, porque considero traduzir, sob certos aspectos, mais difícil do que escrever... Tenham, pois, paciência com minha revisão e a melhorem em tudo que puderem. Estou longe de considerá-la verdadeiramente boa, é apenas conscienciosa e, talvez, passável. (TEIXEIRA, 23 nov. 1970, grifos do autor).
\end{abstract}

Teixeira, para a sua coleção, procura adotar o novo regime de tradução que começava a prevalecer em seu tempo, levando em consideração as regras, normas e convenções prescritas pelos seus colegas tradutores profissionais. A adoção desses critérios para a nova coleção também era importante estratégia para trazer os textos difíceis produzidos fora do Brasil, que atendiam a outro critério de organização do programa de leitura estabelecido: análise da crise atual.

Conclui-se que os textos de Dewey foram reunidos, traduzidos e editados por Anísio Teixeira na Coleção Cultura, Sociedade e Educação como um programa em favor da democracia em tempos difíceis - os da ditadura civil-militar no Brasil e na América Latina - para um público comum. Conformam-se, sob a égide da coleção, como antídoto à violência, à palavra roubada, à supressão e à opressão da liberdade, expressões que deveriam compor toda e qualquer cultura comum ou geral. Nas representações de Teixeira instauradas na coleção, as palavras de Dewey - adjetivado de oráculo da democracia deveriam descortinar, para os leitores comuns, a democracia como "caminho da vida, não só o caminho pessoal, o caminho que nos provê o padrão moral de nossa conduta pessoal" (TEIXEIRA, 1970, p. 8). Neste sentido, há dois deslocamentos dos trabalhos de Dewey que reorganizam seu regime de tradutibilidade: de um lado, sua obra é deslocada do campo da pedagogia, no qual era tradicionalmente inserida, para o da cultura; de outro, deslocada de seu público leitor destinatário - "apenas o dos pedagogos” - para um público 
ampliado e jovem. Teixeira ressignifica o conteúdo dos enunciados desse autor sob a chave da resistência à ditadura e à violência daqueles tempos, alterando completamente o seu regime de tradução.

\section{Referências}

BURKE, Peter. Culturas da tradução nos primórdios da Europa Moderna. In: BURKE, Peter; 0-CHIA HSIA, Roger (Org.). A tradução cultural nos primórdios da Europa Moderna. São Paulo: Edunesp, 2009. p. 13-46.

CERTEAU, Michel. L'invention du quotidien: arts de faire. Paris: Gallimard, 1990.

CHARTIER, Roger. A história cultural: entre práticas e representações. Lisboa; Rio de Janeiro: Difel: Bertrand, 1990.

CHARTIER, Roger. A ordem dos livros: leitores, autores e bibliotecas na Europa entre os séculos XIV e XVIII. Brasilia, DF: UnB, 1994.

COMPANHIA EDITORA NACIONAL. In: DEWEY, John. Experiência e educação. v. 15. São Paulo: CEN, 1971. Orelha.

COMPANHIA EDITORA NACIONAL. In: DEWEY, John. Liberalismo, liberdade e cultura. v. 11. São Paulo: CEN, 1970. Orelha.

COMPANHIA EDITORA NACIONAL. In: WILLIAMS, Raymond. Cultura e sociedade. v. 1. São Paulo: CEN, 1968. Orelha.

DARNTON, Robert. 0 beijo de Lamourette: mídia, cultura e revolução. São Paulo: Companhia das Letras, 2010.

FERREIRA, Octalles Marcondes. Carta a Anísio Teixeira. AT 1966.05.19, CPDOC/FGV. 9 set. 1966.

FONSECA, Silvia Asam da. A bibliotheca do espírito moderno: um projeto para alimentar espíritos. Companhia Editora Nacional (1938-1977). 2010. Tese (Doutorado em Educação: História, Política, Sociedade) Pontifícia Universidade Católica de São Paulo, São Paulo, 2010.

MALTA, Luiz Roberto. Carta a Leenders. AT 1966.05.19, CPDOC/FGV. 8 mar. 1967.

MOLLIER, Jean-Yves. A evolução do sistema editorial francês desde a enciclopédia de Diderot. Livro (Revista do Núcleo dos Estudos do Livro e da Edição), São Paulo, n. 1, p. 61-74, maio 2011.

MOLLIER, Jean-Yves. 0 dinheiro e as letras: história do capitalismo editorial. São Paulo: Edusp, 2010.

NUNES, Clarice. Anísio Teixeira entre nós: a defesa da educação como direito de todos. Educação \& Sociedade, Campinas, v. 21, n. 73, p. 9-38, dez. 2000.

OLIVERO, Isabelle. L'invention de la colection. Paris: IMEC: Maison des Sciences de L'Homme, 1999.

QUEIRÓZ, Thomáz Aquino de. Carta a A. Teixeira. AT 1966.05.19, CPDOC/FG. 19 out. 1966.

RONÁl, Paulo. Escola de tradutores. Rio de Janeiro: José Olympio, 2012.

TEIXEIRA, Anísio. Carta a T. A. de Queiróz. AT 1966.05.19, CPDOC/FGV. 28 out. 1966. 
TEIXEIRA, Anísio. Carta a T. A. de Queiróz. AT 1966.05.19, CPDOC/FGV. 8 nov. 1966.

TEIXEIRA, Anísio. Carta a T. A. de Queiróz. AT 1966.05.19, CPDOC/FGV. 2 dez. 1966.

TEIXEIRA, Anísio. Carta a 0. M. Ferreira. AT 66.05.19, CPDOC/FGV. 13 mar. 1967.

TEIXEIRA, Anísio. Carta a T. A. de Queiróz. AT 1966.05.19, CPDOC/FGV. 19 maio 1967.

TEIXEIRA, Anísio. Carta a 0. M. Ferreira. AT 66.05.19, CPDOC/FGV. 19 jun. 1967

TEIXEIRA, Anísio. Carta a 0. M. Ferreira. AT 66.05.19, CPDOC/FGV. 26 jan. 1968.

TEIXEIRA, Anísio. Carta a T. A. de Queiróz. AT 66.05.19, CPDOC/FGV. 5 fev. 1968.

TEIXEIRA, Anísio. Carta a T. A. de Queiróz: arquivo da Cia Editora Nacional. CMPH/Unifesp. 20 jan. 1970.

TEIXEIRA, Anísio. Carta a T. A. de Queiróz e R. Malta: arquivo da Cia Editora Nacional. CMPH/Unifesp. 23 nov. 1970.

TEIXEIRA, Anísio. Democracia como forma humana de vida. In: DEWEY, John. Liberalismo, liberdade e cultura. São Paulo: Companhia Editora Nacional, 1970. p. 8.

TOLEDO, Maria Rita de A. Coleção atualidades pedagógicas: do projeto político ao projeto editorial (19311981). 2001. Tese (Doutorado em Educação: História, Política, Sociedade) - Pontifícia Universidade Católica de São Paulo, São Paulo, 2001.

TOLEDO, Maria Rita de A. Coleções autorais, traduções e circulação: ensaios sobre a geografia cultural das edições (1930-1980). 2013. Tese (Livre-Docência em História da Educação e Ensino de História) Universidade Federal de São Paulo, Guarulhos, 2013.

TOLEDO, Maria Rita de A. Modelos de leitura em disputa: a concorrência entre as coleções Atualidades pedagógicas e Cultura, sociedade e educação nos bastidores da Companhia Editora Nacional (década de 1960). In: CONGRESSO DE LEITURA, (COLE) 16., 2007, Campinas. Anais... Campinas: ALB, 2007. p. 1-25.

TOLEDO, Maria Rita de A.; CARVALHO, Marta M. C. de. A tradução de John Dewey na coleção autoral Biblioteca de educação. Educação \& Sociedade, Campinas, 2017. (no prelo)

Recebido em: 04.11.2016

Revisões em: 22.02.2017

Aprovado em: 21.03.2017

Maria Rita de Almeida Toledo é professora da Universidade Federal de São Paulo (Unifesp) e coordenadora do Centro de Memória e Pesquisa Histórica, na mesma instituição. Também pela Unifesp, é livre-docente em História da Educação e Ensino de História. 


\section{ERRATA}

Onde se lia:

"Política editorial de traduções: John Dewey na Coleção Cultura, Cociedade e Educação, dirigida por Anísio Teixeira”

Leia-se:

"Política editorial de traduções: John Dewey na Coleção Cultura, Sociedade e Educação, dirigida por Anísio Teixeira” 